\title{
Transmissão de ideias sobre o corpo humano pelo professor de Educação Física escolar e reações percebidas nos alunos
}

\author{
Transmission of ideas about the human body by physical education \\ teacher and school perceived reactions in students
}

\author{
S.F. Carvalho, S.A.P.S. Silva, V.L. Nista-Piccolo, W.W. Moreira, H.C.B. Nunes
}

ARTIGO ORIGINAL | ORIGINAL ARTICLE \begin{abstract}
O presente estudo investiga as ideias de corpo humano que são transmitidas e percebidas por professores de Educação Física (EF), em aulas do Ensino Fundamental, em escolas da região sul da cidade de São Paulo. Para isso, 15 professores responderam, por escrito, às seguintes questões: Que ideias sobre o corpo humano transmite nas suas aulas de EF? Você percebe reações de seus alunos a essas ideias? Os resultados obtidos por meio da análise de conteúdo das respostas revelaram que os professores, quando transmitem ideias de corpo restritas à dimensão física, percebem que as reações de seus alunos se direcionam para aspetos concretos do corpo e para aspetos relacionados ao comportamento dos organismos; quando transmitem ideias de corpo num enfoque na sua dimensão social, percebem que seus alunos demonstram autonomia em termos de aspetos socioculturais e, finalmente, quando transmitem ideias de corpo com um foco psicológico, percebem que seus alunos relacionam as atividades físicas aos aspetos cognitivos. De entre os professores pesquisados, apenas um transmite aos seus alunos ideias de corpo humano por meio dos saberes físico, social e psíquico inter-relacionados.

Palavras-chave: corpo humano, educação física escolar, intervenção pedagógica
\end{abstract}

ABSTRACT

The present study investigates the ideas of the human body transmitted and grasped by the teachers of Physical Education in Basic Education classes. It was carried a research with Physical Education teachers using the following questions: What ideas about the human body are you transmitting in your Physical Education classes? Do you perceive the reactions of your students to these ideas? The analyses of the answers were methodologically followed in these moments: a) reading of the descriptions, b) elaboration of the units of meaning; c) ideographic analysis; d) nomothetic analysis. Results showed that teachers of Physical Education when transmitting ideas of restricted body in the physical dimension, they realized that the reactions of their students were directed to the concrete aspects of the body and to the aspects related to the behavior of the organisms; when they transmitted ideas of body focusing in the social dimension, they realized that their students demonstrated autonomy in social and cultural aspects. Finally, when they transmitted ideas of body in more including ways, they realized that their students related the physical activities to cognitive aspects. The results also showed that among the researched teachers, only one transmitted to the students the idea of the human body through inter-related physical, social and psychological knowledge.

Keywords: human body, school physical education, pedagogical intervention

Submetido: 11.01.2011 | Aceite: 07.03.2011

Sergio Frank Carvalho, Sheila Aparecida Pereira dos Santos Silva, Vilma Leni Nista-Piccolo, Wagner Wey Moreira e Hugo Cesar Bueno Nunes. Universidade São Judas Tadeu, São Paulo, Brasil.

Endereço para correspondência: Sheila Santos Silva, Coordenadoria de Pós Graduação, Rua Taquari, nº546, Mooca, CEP: 03166-000 São Paulo - SP, Brasil

E-mail: sheila.silva@uol.com.br 
O corpo humano exprime-se como um fenômeno e, como tal, é perspetivístico, ou seja, está sujeito a várias conceções a partir de diferentes olhares. As diversas representações sobre o corpo humano expressam-no desde um simples conjunto de músculos e ossos até como um fenômeno transcendental, desde um objeto manipulável até como morada da alma, ou seja, a complexidade do corpo é a própria complexidade do humano, o corpo é o humano e o humano é o corpo (Merleau-Ponty, 1996).

No interior deste panorama complexo é que nos propusemos caminhar, direcionando o olhar para o humano, representado pelo seu corpo no mundo e ao tratamento que lhe é dado no contexto da Educação Física escolar $(\mathrm{EFe})$.

Sendo assim, o objetivo deste estudo é identificar conceções de corpo humano que são transmitidas pelos professores de Educação Física (EF) e as reações que percebem em seus alunos a partir das conceções transmitidas.

\section{O corpo na trajetória histórica da EF Brasileira}

A EF tratou e vem tratando o corpo de diversas formas visando atender às mais diversas determinações ideológicas.

A EF brasileira "nasceu" no século XIX em consequência das preocupações dos médicos higienistas que tentavam reduzir as altas taxas de mortalidade da população brasileira por falta de cuidados básicos de higiene. Neste período, esteve estreitamente vinculada não só à classe médica, como também às instituições militares. Tal combinação de vínculos foi determinante para a construção de uma determinada conceção da disciplina EF, suas finalidades, seu campo de atuação e a forma de ser ensinada.

A obrigatoriedade da EF na escola foi instituída neste período com a função higienista de melhorar a saúde das pessoas e proporcionar atividades que pudessem constituir um físico saudável aos homens tornando-os preparados para atividades físicas e intelectuais e mulheres prontas para cuidar da família e gerar filhos fortes, abordagem que perdurou por todo o século XIX (Castellani Filho, 1988; Medina, 1989; Ghiraldelli Jr., 1992).

No início do século XX, a EFe brasileira era baseada nos métodos europeus (sueco, alemão e posteriormente o francês) que se orientavam por princípios biológicos. Até esse momento, interpretamos que a ideia vigente sobre corpo era a de um corpo físico. Na década de 30 , a EF voltou a servir como instrumento de ideologia do poder constituído, agora visando atender às necessidades de segurança nacional e à demanda de mão-de-obra que assegurava o processo acelerado de industrialização que estava sendo implantado no país. Esta tendência, denominada militarista, contribuía para a constituição do corpo disciplinado, submisso, apto físico e moralmente (Bracht, 1989; Bracht \& Mello, 1992).

Com o fim do Estado Novo, iniciou-se uma série de discussões envolvendo como temática a educação e, especificamente, a EF como elemento curricular, tendo como consequência a proposta de um novo enfoque que visava integrá-la como disciplina educativa no âmbito da rede pública de ensino.

Do final do Estado Novo até a promulgação da Lei de Diretrizes e Bases da Educação Nacional de 1961, houve um amplo debate sobre o sistema de ensino brasileiro. Nessa lei ficou determinada a obrigatoriedade da EF para o ensino primário e médio (Secretaria de Educação Fundamental do Brasil, 1998).

$\mathrm{Na}$ década de 60 , a EF brasileira introduziu a utilização do método desportivo generalizado, o que significou uma contraposição aos métodos de ginástica tradicionais que serviam como base do conteúdo pedagógico até então. Além da influência (d)esportiva, a EF brasileira sofreu as influências da tendência tecnicista que surgia fortemente em 1964 e que lhe imprimiu um caráter instrumental voltado para o desempenho técnico e físico do aluno.

$\mathrm{Na}$ década de 70 , a EF brasileira retomou funções ideológicas importantes para a manutenção da ordem e do progresso nacional. As atividades (d)esportivas também passaram a 
ser vistas como alternativas que colaboravam na melhoria da força de trabalho para impulsionar a economia brasileira e para o controle das manifestações políticas das massas. Com essa finalidade, o governo ditatorial manifestava grande interesse em incentivar a $\mathrm{EF}$ e, principalmente, o esporte, divulgando os feitos dos atletas de alto nível, transformados em "heróis da pátria". Com esse incentivo, a iniciação (d)esportiva posicionava-se como um dos eixos fundamentais no ensino da EF.

Na década de 80, alguns estudiosos da área, preocupados com os efeitos desse modelo (d)esportivista e com a influência da ideologia dominante, passaram a criticar enfaticamente as práticas excludentes e seletivas adotadas por muitos professores em suas aulas. Podemos afirmar que, quer como veículo de transmissão ideológica, quer como veículo de desenvolvimento de atletas e equipes (d)esportivas, interpretamos que a ideia veiculada de corpo era a de um corpo social uma vez que atendia a interesses que visavam direcionar e condicionar a sociedade.

Os debates eram mais férteis e apontavam o rumo das novas tendências da EF brasileira. As relações entre EF e sociedade passaram a ser discutidas sob a influência das teorias críticas da educação que tinha como intenção a formação do corpo cidadão, crítico, autônomo e politizado (Coletivo de Autores, 1992; Ghiraldelli, 1992).

Atualmente concebe-se a existência de algumas abordagens para a EFe no Brasil que resultam da articulação de diferentes teorias psicológicas, sociológicas e conceções filosóficas, caracterizando uma visão complexa sobre o corpo.

Diante deste breve relato histórico da EF brasileira, notamos que o corpo humano foi entendido a partir de várias perspetivas e intencionalidades, tratado de várias maneiras e manipulado para atender a diversos interesses. Esta diversidade de intenções e conceções sobre o corpo humano ainda estão presentes em diversos setores sociais, incluindo os espaços destinados à EFe.
Acreditamos, portanto, que os professores de EF assumem um papel importante num contexto que transmite intencionalmente, ou não, ideias sociais sobre o corpo humano. Baseados nessa premissa, os professores podem adotar, consciente ou inconscientemente, diferentes discursos que visam adequar o corpo do seu aluno ao atendimento de objetivos específicos compatíveis com as crenças educativas vigentes.

A partir dessa realidade, pensamos que é importante refletir sobre as ideias de corpo humano que são transmitidas e percebidas pelos professores de EF, no contexto escolar. Direcionamos, portanto, nosso olhar a questões referentes à prática pedagógica, interesses sociais e possíveis consequências para o tratamento dado aos alunos, geradas a partir das ideias de corpos que podem ser transmitidas pelos professores em seus discursos durante as suas aulas de EF na escola.

\section{MÉTODO}

\section{Amostra}

O estudo foi realizado com professores de escolas da rede pública estadual de ensino, situadas no extremo sul da capital paulista, nos bairros do Grajaú, Jardim Varginha, Jardim das Imbuias, Jardim Colonial, Icaraí, Vila São José, Rio Bonito e Interlagos, tendo em conta a facilidade de acesso a essas escolas.

A participação dos sujeitos na pesquisa foi livre e consentida e o grupo selecionado de acordo com o critério de acessibilidade e de demonstração de disponibilidade para colaborar com a pesquisa, sendo distribuídos conforme o Quadro 1.

\section{Procedimentos}

O presente estudo caracteriza-se como uma pesquisa qualitativa, numa perspetiva fenomenológica, com base na análise do fenômeno situado (Martins \& Bicudo, 1989; Moreira, 1995; Silva, 1996) com o objetivo de desvelar as conceções de corpo humano, transmitidas e percebidas pelos professores de EF a partir da análise de seus discursos. 
Os discursos foram gerados a partir das perguntas, respondidas por escrito, durante uma reunião de Delegacia de Ensino, sem comunicação entre os pesquisados:

i) Que ideias sobre o corpo humano você transmite em suas aulas de EF?

ii) Você percebe reações de seus alunos a essas ideias?

O projeto de pesquisa foi aprovado pelo COEP - Comitê de Ética em Pesquisa da Universidade São Judas Tadeu.

Quadro 1

Características dos sujeitos pesquisados

\begin{tabular}{lcc}
\hline \multicolumn{1}{c}{ Variável } & $\mathrm{n}$ & $\%$ \\
\hline Idade & & \\
20-30 anos & 5 & 33.3 \\
30-40 anos & 6 & 40.0 \\
$>$ > 0 anos & 4 & 26.7 \\
Tempo de Formação & & \\
$<1$ ano & 1 & 6.6 \\
1-5 anos & 4 & 26.7 \\
5-10 anos & 6 & 40.0 \\
$>10$ anos & 4 & 26.7 \\
Género & & \\
Masculino & 6 & 40.0 \\
Feminino & 9 & 60.0 \\
\hline
\end{tabular}

\section{Análise dos Dados}

As respostas passaram pelos três momentos de análise: descrição, redução e compreensão (França, 1989; Martins, 1992; Martins \& Bicudo, 1989; Moreira, 1995). As unidades de significados identificadas nos discursos individuais (análise ideográfica) foram, posteriormente, agrupadas numa matriz (nomotética) com a finalidade de oferecer uma visão geral sobre $o$ assunto pesquisado.

\section{APRESENTAÇÃO E DISCUSSÃO DOS RESULTADOS}

Para elaboração da análise nomotética foi necessário fazer agrupamentos a partir das unidades de significados extraídas das respostas dos sujeitos, constituindo, então, as categorias que orientaram a análise.
No Quadro 2 são apresentadas as ideias que os professores afirmam transmitir sobre corpo humano durante suas aulas e, no Quadro 3, as reações que eles percebem de seus alunos em relação a essas ideias.

$\mathrm{Na}$ horizontal, ao alto da matriz, à direita, codificados com os códigos que vão de D1 até D15, são indicados os discursos dos quinze sujeitos envolvidos na pesquisa.

$\mathrm{Na}$ margem esquerda da matriz e numa sequência vertical de cima para baixo, encontram-se os agrupamentos de unidades de significado, formando categorias elaboradas pelos pesquisadores, nas quais são apresentadas as convergências extraídas da leitura dos discursos.

O símbolo " $\times$ " regista a menção de determinada ideia no discurso do sujeito da respetiva coluna.

O total $\left(\sum\right)$ registado na margem direita da matriz foi citado para facilitar o trabalho de identificação dos fatores que surgiram com maior frequência e, também, os aspetos idiossincráticos.

A leitura da matriz nomotética permite identificar as convergências existentes entre as categorias, e é a partir delas que podemos levantar algumas considerações, realizando um trabalho interpretativo.

O Quadro 4 permite analisar as relações entre as ideias transmitidas e as reações percebidas pelos próprios professores de $\mathrm{EF}$, e que foram organizadas em três grupos.

Com isso, podemos interpretar as seguintes considerações:

Grupo I: Os professores de EF, quando transmitem ideias de corpo Físico, percebem que as reações de seus alunos se direcionam para os aspetos concretos do corpo e para os aspetos relacionados com o comportamento dos organismos. A intervenção pedagógica destes professores pesquisados volta-se para o desenvolvimento do ser humano de uma maneira fragmentada, limitada aos aspetos físicos e biológicos dos alunos.

Para esses professores, as aulas de EF devem priorizar os conhecimentos fisiológicos 
Quadro 2

Ideias transmitidas pelos professores nas aulas de EF

\begin{tabular}{|c|c|c|c|c|c|c|c|c|c|c|c|c|c|c|c|c|}
\hline \multirow{3}{*}{ Agrupamentos } & \multicolumn{15}{|c|}{ Discursos } & \multirow{3}{*}{$\sum$} \\
\hline & $\mathrm{D}$ & $\mathrm{D}$ & $\mathrm{D}$ & $\mathrm{D}$ & $\mathrm{D}$ & $\mathrm{D}$ & $\mathrm{D}$ & $\mathrm{D}$ & $\mathrm{D}$ & $\mathrm{D}$ & $\mathrm{D}$ & $\mathrm{D}$ & $\mathrm{D}$ & $\mathrm{D}$ & $\mathrm{D}$ & \\
\hline & 1 & 2 & 3 & 4 & 5 & 6 & 7 & 8 & 9 & 10 & 11 & 12 & 13 & 14 & 15 & \\
\hline \multicolumn{17}{|l|}{ 1. Ideias de corpo Físico } \\
\hline $\begin{array}{l}1.1 \text { O corpo como um objeto físico a ser } \\
\text { conhecido para ser ajustável em sua utilidade. }\end{array}$ & $\times$ & & $\times$ & $\times$ & $\times$ & $\times$ & & & $\times$ & & $\times$ & & & & $\times$ & 8 \\
\hline $\begin{array}{l}\text { 1.2 As funções mecânicas e biológicas que } \\
\text { levam o corpo a desenvolver habilidades. }\end{array}$ & $x$ & $\times$ & & & $\times$ & $x$ & & $x$ & & & & & $\times$ & & $x$ & 7 \\
\hline 1.3 O exercício físico como sinônimo de saúde. & & $\times$ & & & $\times$ & & & & & & $\times$ & & & & $x$ & 4 \\
\hline $\begin{array}{l}\text { 1.4 A atividade física como sinônimo de } \\
\text { qualidade de vida. }\end{array}$ & & $\times$ & & & $\times$ & & $\times$ & $x$ & & & & & & & & 4 \\
\hline $1.5 \mathrm{O}$ corpo humano como máquina controlável. & & & & $\times$ & & & & & & & & & & & & 1 \\
\hline \multicolumn{17}{|l|}{ 2. Ideias de corpo Social } \\
\hline $\begin{array}{l}2.1 \text { As representações de corpo humano no } \\
\text { âmbito sociocultural. }\end{array}$ & & & & & & & $\times$ & & & $\times$ & & $x$ & & $x$ & & 4 \\
\hline $\begin{array}{l}2.2 \text { Corpos compreendendo as regras de } \\
\text { convivência. }\end{array}$ & & & & & & & & & $\times$ & $\times$ & & $\times$ & & $x$ & & 4 \\
\hline $\begin{array}{l}\text { 2.3 Peculiaridades culturais referentes aos } \\
\text { gestos. }\end{array}$ & & & & & & & $\times$ & & & & & $x$ & & & & 2 \\
\hline $\begin{array}{l}\text { 2.4 As aulas de EF como espaço fundamental no } \\
\text { tratamento dos corpos. }\end{array}$ & & & & & & & $\times$ & & & & & & & & & 1 \\
\hline \multicolumn{17}{|l|}{ 3. Ideias de corpo Psíquico } \\
\hline $\begin{array}{l}3.1 \text { O corpo humano como algo que não pode } \\
\text { ser compreendido isoladamente. }\end{array}$ & & & $\times$ & $x$ & & & & & $\times$ & & & & & & $\times$ & 4 \\
\hline $\begin{array}{l}3.2 \mathrm{O} \text { esporte como atividade essencial que } \\
\text { estimula conjuntamente o corpo e a mente. }\end{array}$ & & $\times$ & & & & & & & & & & & & & & 1 \\
\hline $3.3 \mathrm{O}$ corpo humano integrado à alma. & & & & & & & & & $\times$ & & & & & & & 1 \\
\hline
\end{tabular}

Quadro 3

Reações dos alunos percebidas pelos professores

\begin{tabular}{lcccccccccccccccc} 
& \multicolumn{11}{c|}{ Discursos } \\
Agrupamentos & $\mathrm{D}$ & $\mathrm{D}$ & $\mathrm{D}$ & $\mathrm{D}$ & $\mathrm{D}$ & $\mathrm{D}$ & $\mathrm{D}$ & $\mathrm{D}$ & $\mathrm{D}$ & $\mathrm{D}$ & $\mathrm{D}$ & $\mathrm{D}$ & $\mathrm{D}$ & $\mathrm{D}$ & $\mathrm{D}$ & $\Sigma$ \\
& 1 & 2 & 3 & 4 & 5 & 6 & 7 & 8 & 9 & 10 & 11 & 12 & 13 & 14 & 15 &
\end{tabular}

1. Coerentes com as ideias de corpo Físico

1.1 Relacionam ideias de corpo físico com modalidades esportivas específicas.

1.2 Expressam ideias exclusivamente físicas.

1.3 Identificam as ideias aprendidas nas atividades de EF.

\begin{tabular}{|c|c|c|c|c|c|c|c|c|c|c|c|}
\hline$x$ & $x$ & $x$ & $x$ & $\times$ & $\times$ & & $x$ & $x$ & $\times$ & $x$ & $x$ \\
\hline$\times$ & & & $\times$ & $x$ & & $x$ & $\times$ & & $x$ & $x$ & $x$ \\
\hline ה & $\times$ & $\times$ & & $x$ & $\times$ & & $x$ & & $x$ & & \\
\hline
\end{tabular}

2. Coerentes com as ideias de corpo Social

2.1 Assumem nova postura diante das pessoas a sua volta.

2.2 Compartilham ideias fora do contexto escolar.

2.3 Contestam as ideias transmitidas pelo professor.

2.4 Demonstram curiosidades e questionamentos



3. Coerentes com as ideias de corpo Psíquico

3.1 Relacionam as atividades corporais com a saúde física e mental. 
Quadro 4

Relação entre as ideias transmitidas e reações percebidas

\begin{tabular}{|c|c|c|c|}
\hline Grupo & Discursos & $\begin{array}{c}\text { Ideias } \\
\text { transmitidas }\end{array}$ & Reações percebidas \\
\hline I & $\begin{array}{c}\mathrm{D} 1, \mathrm{D} 2, \mathrm{D} 3, \mathrm{D} 4, \\
\mathrm{D} 5, \mathrm{D} 6, \mathrm{D} 7, \mathrm{D} 8, \\
\mathrm{D} 9, \mathrm{D} 11, \mathrm{D} 13, \\
\mathrm{D} 15\end{array}$ & Corpo Físico & $\begin{array}{l}\text { Relacionam ideias de corpo físico com modalidades } \\
\text { esportivas específicas. } \\
\text { Expressam ideias exclusivamente físicas. } \\
\text { Identificam as ideias aprendidas nas atividades de EF. }\end{array}$ \\
\hline II & $\begin{array}{c}\text { D7, D9, D10, } \\
\text { D12, D14 }\end{array}$ & Corpo Social & $\begin{array}{l}\text { Assumem nova postura diante das pessoas à sua volta. } \\
\text { Compartilham ideias fora do contexto escolar. } \\
\text { Contestam as ideias transmitidas pelo professor. } \\
\text { Demonstram curiosidades e questionamentos. }\end{array}$ \\
\hline III & $\begin{array}{c}\mathrm{D} 2, \mathrm{D} 3, \mathrm{D} 4 \\
\mathrm{D} 9, \mathrm{D} 15\end{array}$ & Corpo Psíquico & $\begin{array}{l}\text { Relacionam as atividades corporais com a saúde física e } \\
\text { mental. } \\
\text { Compreendem e respeitam a diversidade humana. } \\
\text { Relacionam as ideias de corpo psíquico com o estado de } \\
\text { saúde. }\end{array}$ \\
\hline
\end{tabular}

que estudam os processos mecânicos, físicos e bioquímicos dos organismos vivos, tentando compreender como as várias estruturas funcionam.

Em alguns discursos foi possível evidenciar a importância atribuída aos aspetos objetivos e concretos do corpo. Foi possível perceber, também, que os professores procuram transmitir conceitos que levem os alunos a compreender o funcionamento e a interação dos sistemas biológicos (endócrino, respiratório e circulatório), a fim de atender algumas expectativas específicas como a saúde e o aperfeiçoamento da qualidade de vida. O caráter físico-biológico predominante nessas aulas de EFe denuncia uma abordagem do corpo marcadamente positivista.

A padronização das aulas de EF pode ser um fator comum presente nas práticas pedagógicas daqueles que transmitem conceções de um corpo exclusivamente físico e/ou biológico. Concordamos com Moreira (1995) quando afirma que, ao adotar métodos pedagógicos padronizados, os professores de EF visam "ajustar" os corpos dos alunos para as necessidades utilitárias específicas.
Portanto, acreditamos que os alunos, que são influenciados pelas ideias destes professores, passam a ver o corpo apenas em sua estrutura material, desarticulado, portanto, do todo que o constitui. Esta estrutura material assimila-se a um "corpo máquina" que, no contexto da $\mathrm{EF}$, deve ser rápido, habilidoso e, acima de tudo, competitivo.

O corpo humano como máquina pode ser entendido como um conjunto de diversas peças ou objetos no sentido de desenvolver e melhorar habilidades. A preocupação central referese ao bom funcionamento das partes como engrenagens que movimentam a extraordinária máquina humana. Quanto melhor o ajuste das engrenagens melhor será o funcionamento do corpo.

Em Descartes (1979) encontramos esse tipo de pensamento que compara o corpo humano, pela disposição de seus órgãos, a um relógio composto de rodas e contrapeso: "... esse movimento que acabo de explicar segue-se tão necessariamente da simples disposição dos órgãos que se podem ver a olho nu no coração, e do calor que se pode sentir com os dedos, e da natureza do sangue que se pode conhecer por experiência, como o de um relógio segue- 
se da força, da situação e da figura de seus contrapesos e rodas ..." (p. 34-35).

Pensando, ainda, no corpo como uma máquina, entendemos que ele pode ser visto como um objeto operacionalizável, algo que pode ser dominado. Este corpo dominável pode, portanto, da mesma forma que uma máquina, ser colocado ou tirado de funcionamento, caso não esteja a corresponder aos desejos do seu maquinista - o corpo também como «coisa» que se possui.

"O corpo humano, ao ser comparado com uma máquina hidráulica, recebe uma educação que o considera apenas em seu aspeto mecânico, sem vontade própria, sem desejos e sem o reconhecimento da intencionalidade do movimento humano, o qual é explicado através da mera reação a estímulos externos, sem qualquer relação com a subjetividade ..." (Mendes \& Nóbrega, 2004, p.125).

Partindo deste conceito e retomando o contexto da realidade escolar, podemos afirmar que estes professores de EF valorizam, portanto, a perna que faz o gol(o) ou a mão que encesta. $\mathrm{O}$ aluno passa a ser uma máquina mensurável pela sua habilidade física específica, quem acerta no alvo é melhor do que aquele que não acerta.

Para que isto não aconteça, estes professores devem refletir criticamente sobre sua prática e tentar inserir situações de aprendizagem que possibilitem respeitar as diferenças.

Os PCN's (Secretaria de Educação Fundamental do Brasil, 1998) para EF no Ensino Fundamental descrevem que "... as situaçôes de ensino e aprendizagem devem contemplar as possibilidades de o aluno arriscar, vacilar, decidir, simular $e$ errar, sem que isso implique algum tipo de humilhação ou constrangimento" (p. 55).

Consideração sobre o Grupo II: Os professores de EF quando transmitem ideias de corpo Social percebem que seus alunos demonstram autonomia em termos de aspetos socioculturais. A intervenção pedagógica desses professores pesquisados volta-se para o desenvolvimento do ser humano por meio dos aspetos sociais. O corpo, na conceção desses professores, é apresentado aos alunos como um fenó- meno resultante das diferentes representações advindas dos vários contextos. Este corpo busca compreender a sociedade, suas normas e seus valores, no qual a linguagem corporal torna possível a identificação do grupo social a que pertence.

De acordo com os $\mathrm{PCN}^{\prime}$ s para EF no Ensino Fundamental, o ser humano desde suas origens produziu cultura: "...sua história é uma história de cultura na medida em que tudo o que faz é parte de um contexto em que se produzem e reproduzem conhecimentos. O conceito de cultura é aqui entendido, simultaneamente, como produto da sociedade e como processo dinâmico que vai constituindo e transformando a coletividade à qual os indivíduos pertencem, antecedendo-os e transcendendo-os" (Secretaria de Educação Fundamental do Brasil, 1998, p. 27).

Ao depararmo-nos com os discursos dos sujeitos, foi possível perceber que eles se preocupam em transmitir aos alunos uma ideia de que o corpo, paradoxalmente, se comunica mais do que o próprio indivíduo, já que é por meio dele que se dá a primeira perceção do mundo exterior: "... no corpo estão inscritos todas as regras, todas as normas e todos os valores de uma sociedade específica, por ser ele o meio de contato primário do indivíduo, com o ambiente que o cerca" (Daólio, 1995, p. 39).

As discussões em torno dos aspetos socioculturais expressos nas aulas de EF, segundo os próprios professores, possibilitam que eles apresentem aos alunos as diferentes representações de corpo humano nos diversos contextos sociais. Essas representações referem-se às regras de convivência existentes em diferentes sociedades, as peculiaridades culturais como as expressões gestuais e por fim, como devem ser tratados os corpos no micro espaço social da EFe.

Em consequência dessas discussões, os sujeitos afirmam que as reações de seus alunos percebidas por eles, demonstram que passaram a assumir uma nova postura diante das pessoas à sua volta, compartilhando ainda essas ideias com outras pessoas fora do contexto escolar, além de se terem tornado mais críticos. 
Para os professores entrevistados, essas reações devem-se ao contexto social das aulas de EF. Este contexto refere-se aos princípios de ética, respeito ao próximo e regras de convivência apresentadas nas aulas e assimiladas pelos alunos.

"Assim, o objetivo da ética na escola é desenvolver a autonomia dos indivíduos, propiciando a eles refletir sobre algo, assimilar e questionar este conjunto de regras e normas, para permitir que tenham consciência de uma série de comportamentos adequados para crescer em sociedade. Valores e atitudes podem, se estiverem incluídas nos conteúdos de ensino, ser trabalhados em todas as disciplinas. Portanto, a EF, como qualquer outra disciplina, tem responsabilidade na concretização de todo esse processo" (Guimarães, Pellini, Araújo, \& Mazzini, 2001, p.19).

Sabemos que é importante transmitir aos alunos conceções de um corpo social, no entanto, percebemos nos discursos dos professores que outros aspetos igualmente relevantes, pertinentes à $\mathrm{EFe}$, ficaram de fora de suas práticas pedagógicas, relativos às dimensões física, psíquica e filosófica.

Consideração sobre o Grupo III: Os professores de EF quando transmitem ideias do corpo Psíquico percebem que seus alunos relacionam as atividades físicas com aspetos cognitivos. A intervenção pedagógica desses professores pesquisados volta-se para a tomada de consciência que une o ser corpo ao ser mente e ao ser espírito, no entanto, por vezes não associa, de maneira eficaz, a consciência ao ser sociedade. Em seus discursos, os sujeitos relatam que transmitem aos alunos que o corpo humano não pode ser compreendido isoladamente, que o esporte estimula conjuntamente o corpo e a mente, e ainda, que o corpo humano é integrado pela alma.

Podemos perceber que a primeira ideia transmitida se refere principalmente à autoperceção corporal do aluno. Nesta perspetiva, entendemos que esses professores se preocupam em estimular a reflexão dos alunos em relação aos movimentos e suas possíveis aplicações na descoberta das partes do corpo e de seu equilíbrio.
A segunda ideia refere-se aos estímulos psíquicos resultantes, principalmente, das reações emocionais que emergem nas diversas situações esportivas presentes nas aulas de EF. Em relação a isto, Brandão (2000) descreve que as reações emocionais podem facilitar ou dificultar um determinado desempenho, isto porque elas são resultantes de uma interpretação cognitiva determinada por determinada situação geradora de estresse.

Já na terceira ideia apresentada pelos sujeitos, que se refere ao corpo essencialmente unido à alma, é possível identificar certa preocupação em não transmitir aos alunos a conceção de um corpo exclusivamente físico. Reforçam junto dos alunos o apelo para que se percebam e sintam compostos de corpo e alma.

Ao analisarmos as ideias transmitidas e as reações percebidas, entendemos que, por meio da visão psíquica, é possível mudar o comportamento e atitudes dos alunos levando-os a contemplar e respeitar as pessoas e suas diferenças. No entanto, no discurso dos professores referente ao corpo psíquico, observamos que tal ênfase acabava, por vezes, minimizando e subalternizando a discussão a respeito dos aspetos relacionados ao corpo físico e ao corpo social.

Porém, apenas um professor de EF (D9) transmitiu aos seus alunos ideias de corpo humano por meio dos saberes físico, social e psíquico de modo inter-relacionado. Um único professor declara conceber o corpo humano como a base da perceção e organização da vida humana nos sentidos físico, social e psíquico. Segundo ele, o falar, olhar, andar, sentir e pensar são peculiaridades que representam modos de uma vida em que o corpo é o ser humano. Ou seja, o ser humano no mundo está representado por meio do seu corpo. O ser humano na concretude de seu corpo é, segundo Morin (2003), composto pelas conceções físicas, biológicas, psíquicas, culturais, sociais e históricas. Nessa perspetiva, o corpo deixa de ser análise para se tornar síntese, o homem como um "corpo no mundo" é uma totalidade que age movida por intenções. 
Sabendo disso, não podemos mais aceitar a decomposição do todo em partes desconectadas e concordamos que "... o corpo não é, pois um objeto. Pela mesma razão, a consciência que tenho não é um pensamento, quer dizer que não posso decompôlo e recompô-lo para formar dele uma ideia clara. Sua unidade é sempre implícita e confusa. Ele é sempre outra coisa além do que é, sempre sexualidade ao mesmo tempo que liberdade, enraizado na natureza no momento mesmo em que se transforma pela cultura, nunca fechado sobre si mesmo, e nunca ultrapassado. Se se trata do corpo de outro ou de meu próprio corpo, não tenho outro meio de conhecer o corpo humano senão vivendo-o, quer dizer, retomar por minha conta o drama que o atravessa e me confundir com ele. Sou, pois meu corpo..." (Cavalari, 1996, pp. 47-48).

O discurso desse professor, D9, aponta uma visão complexa, a partir da qual só se é possível transmitir ideias sobre o corpo humano se todos os saberes estiverem inter-relacionados, ou seja, o corpo humano entendido, a um só tempo, como físico, social e psíquico.

É importante ressaltar que este é um professor recém-formado. Isto pode demonstrar que as formações mais recentes, realizadas em cursos superiores de EF mais atualizados, apresentem propostas curriculares que conseguem relacionar os saberes necessários à educação. Essa educação atual e contemporânea implica a inserção de um corpo humano em um mundo significativo, a relação dialética do corpo consigo mesmo, implica uma relação dialogo-ontológica com outros corpos expressivos e com os objetos do seu mundo, o que significa que ele se torna espaço expressivo por demarcar o início e o fim de nossa condição humana. Dessa forma, nosso corpo, como corpo vivenciado, não é o início e nem o fim, é sempre o meio no qual e por meio do qual o processo da vida se perpetua.

\section{CONCLUSÕES}

Este estudo apresentou alguns indicativos do que são as ideias sobre corpo, transmitidas na EFe. Possibilidades que evidenciam, acima de tudo, a diversidade humana por meio de diferentes conceções sobre o corpo que os professores dessa área de conhecimento ensinam em suas práticas pedagógicas. Além disso, os sujeitos pesquisados declaram as reações que eles percebem em seus alunos, face ao que transmitem.

Se pensarmos que há algum tempo a EF era praticamente dominada por uma visão reducionista de corpo, podemos refletir que as ideias de corpo desveladas neste estudo parecem mostrar uma evolução dessas conceções. Percebemos que a visão que vislumbra apenas o fragmento físico corporal ainda está presente e continua sendo valorizada por alguns professores; no entanto, nota-se que ela não é mais a única ideia a ser veiculada nas aulas de EF na escola. Há outras duas conceções que foram desveladas: uma que se refere à dimensão social do corpo e outra que se refere ao corpo psíquico.

Além disso, identificamos por meio do discurso de um professor, a emergência no cenário pedagógico da $\mathrm{EF}$ de uma visão complexa sobre o corpo humano que permite que os saberes físicos, psíquicos e sociais se interrelacionem.

$\mathrm{Na}$ conceção física percebemos que os professores expressam significados de um corpo mecânico, controlável e ajustável à sua utilidade. E, desta forma, seus alunos buscam ajustar seus corpos para corresponderem às exigências técnicas presentes em funções específicas, referindo-se unicamente aos aspetos físicos e biológicos.

Na conceção social, os professores transmitem ideias que explicam o contexto das representações corporais, das regras de convivência, do espaço social e dos gestos corporais. Com isso, identificam que seus alunos ganham mais autonomia para assumir posturas, compartilhar, questionar e contestar ideias.

$\mathrm{Na}$ conceção de corpo com enfoque psíquico, os professores preocupam-se em associar o corpo à mente e, como consequência, percebem que seus alunos conseguem relacionar os aspetos físicos e cognitivos e, além disso, passam a compreender melhor o que é a diversidade humana. 
Além das ideias transmitidas e reações percebidas, foi possível perceber que os métodos pedagógicos utilizados pelos professores de EF divergem entre si. Alguns professores não permitem estabelecer as relações mútuas e as influências recíprocas entre as partes e o todo de um corpo humano complexo situado em um mundo complexo.

Outros professores preocupam-se em transmitir ideias centradas na soma de fragmentos (físico + social, físico + psíquico, social + psíquico). O entendimento sobre o fenômeno corpo humano por meio da soma de fragmentos é, sem dúvida, mais abrangente que o entendimento fragmentado, não, porém, ainda suficientemente significativo, uma vez que a simples soma das partes não representa o todo.

Por outro lado, percebemos no discurso de um dos professores, que o entendimento do corpo humano complexo, integral ou global é possível e viável dentro da prática pedagógica da EF na escola. A relação feita por este professor entre as ideias de corpo físico, social e psíquico, levou-nos a crer que ele tem consciência que o conjunto das diversas partes deva ser ligado a um fenômeno de modo integrado e orgânico. Este professor parece ter consciência de que o todo tem qualidades ou propriedades que não são encontradas nas partes, se estas estiverem isoladas uma das outras, e, deste modo, certas qualidades ou propriedades das partes podem ser inibidas pelas restrições provenientes do todo que detém o primado ontológico.

Aqui identificamos e relacionamos idéias de corpo humano a partir dos discursos dos sujeitos. Outros estudos podem surgir desvelando outros aspetos do fenômeno, caso se lance mão na análise de campo da observação do pesquisador. Entendemos que este debate merece maiores aprofundamentos e novos questionamentos que, ao serem sinalizados neste estudo, possam vislumbrar uma prática educativa ressignificada de valores, atitudes, posicionamentos e entendimentos do significado do corpo, corpo-aluno ou corpo humano.

\section{Agradecimentos:}

Os autores gostariam de agradecer ao Governo do Estado de São Paulo pelo apoio ao desenvolvimento da pesquisa sob a forma de Bolsa Mestrado.

\section{Conflito de Interesses:}

Nada a declarar.

\section{Financiamento:}

Nada a declarar.

\section{REFERÊNCIAS}

Bracht, V. (1989). Educação Física: A busca da autonomia pedagógica. Revista da Educação Física, 1(1), 12-18.

Bracht, V., \& Mello, R. A. (1992). Educação Física: Revisão crítica e perspectiva. Revista da Educação Física, 3(1), 3-12.

Brandão, M. R. (2000). Fatores de stress em jogadores de futebol profissional (Tese de Doutorado não publicada). Unicamp, Campinas, SP, Brasil.

Castellani Filho, L. (1988). Educação Física no Brasil: A história que não se conta. Campinas: Papirus.

Cavalari, R. M. (1996). O pensamento filosófico e a questão do corpo. In S. S. Neto (Ed.), Corpo para malhar ou para comunicar? (pp. 39-50). São Paulo: Cidade Nova.

Coletivo de Autores (1992). Metodologia do ensino de educação física. São Paulo: Cortez.

Daólio, J. (1995). Da cultura do corpo. Campinas: Papirus.

Descartes, R. (1979). Discurso do método. São Paulo: Abril Cultural.

França, C. (1989). Psicologia fenomenológica: Uma das maneiras de se fazer. Campinas: Unicamp.

Ghiraldelli Jr., P. (1992). Educação física progressista: A pedagogia crítico-social dos conteúdos e a educação física. São Paulo: Loyola.

Guimarães, A., Pellini, F., Araújo, S., \& Mazzini, J. (2001). Educação física escolar: Atitudes e valores. Motriz, 7(1), 17-22.

Martins, J. (1992). Um enfoque fenomenológico do currículo: Educação como poiesis. São Paulo: Cortez.

Martins, J., \& Bicudo, M. (1989). A pesquisa qualitativa em psicologia: Fundamentos e recursos básicos. São Paulo: EDUC.

Medina, J. P. (1989). A educação física cuida do corpo e ... "mente". Campinas: Papirus. 
Mendes, M. I., \& Nóbrega, T. P. (2004). Corpo, natureza e cultura: Contribuições para a educação. Revista Brasileira de Educação, 27, 125-137.

Merleau-Ponty, M. (1996). Fenomenologia da percepção. São Paulo: Martins Fontes.

Moreira, W. W. (1995). Educação física escolar: Uma abordagem fenomenológica. Campinas: Unicamp.

Morin, E. (2003). Os sete saberes necessários à educação do futuro. São Paulo: Cortez.
Secretaria de Educação Fundamental do Brasil (1998). Parâmetros curriculares nacionais: Educação Física, terceiro e quarto ciclo do ensino fundamental. Brasília: MEC/SEF.

Silva, S. A. (1996). A pesquisa qualitativa em Educação Física. Revista Paulista de Educação Física, 10(1), 87-98.

(cc) EY-Nc Todo o conteúdo da revista Motricidade está licenciado sob a Creative Commons, exceto quando especificado em contrário e nos conteúdos retirados de outras fontes bibliográficas. 